\title{
Design visual, hegemonia e ativismo
}

André Vieira Queiroz;

André Villas-Boas

resumo:

Este estudo se baseia em dissertação de mestrado defendida na Universidade Federal do Rio de Janeiro (UFRJ) e objetiva articular a inserção social do design visual à teoria da hegemonia de Antonio Gramsci, particularmente a partir das interpretações de ACANDA (2006) e WILLIAMS (2005). Utilizando ainda a teoria do campo de Bourdieu, o artigo defende uma postura crítica do designer como cidadão e profissional, inspirado por MATIAS (2014), e procura mostrar sua viabilidade, abordando também a experiência concreta do coletivo brasileiro Design Ativista, que atua principalmente por meio da internet.

palavras-chave: teoria crítica; Gramsci; práxis; teoria do campo; \#designativista 
O design visual, tal como o concebemos hoje, tem suas origens num ambiente de vanguarda portanto, contra-hegemônico (Gramsci, Williams) -, surgindo como campo potencialmente autônomo (Bourdieu) a partir da premissa de "trazer a arte à vida" das vanguardas históricas europeias. O aprofundamento e a expansão capitalistas logo o absorvem, pela necessidade de especialização das instâncias de produção e de instrumentos que garantam a preservação e a disseminação de sua lógica. A influência dos paradigmas da publicidade dos EUA e a gradual proeminência da escola funcionalista a partir da Europa fazem com que o próprio campo do design visual dê ênfase não à pluralidade e à quebra de paradigmas, mas à universalização de soluções e à reprodução do capital. Em suas instâncias dominantes, o design visual assume, assim, as concepções historicamente formuladas pelas classes dirigentes e passa a atuar diretamente na naturalização destas concepções. Tal ocorre como se fossem manifestações dadas, "naturais" da cultura, num processo de incorporação que oculta a historicidade das relações sociais. No entanto, como este artigo procurará mostrar, a postura crítica não só está entranhada na história do design visual como é ontologicamente pertencente a ele.

O objetivo deste estudo é refletir sobre como se dá este processo e como o design (e os designers) atuam em sua lógica - reflexão esta sob a ótica da teoria crítica (Horkheimer), qual seja, da análise crítica sobre o fenômeno estudado (e sobre a própria atuação do agente que o estuda) e a orientação para a emancipação frente às estratégias de dominação vigentes (NOBRE, 2004:34-44). Não se trata de, tal qual uma vestal de Curitiba, apontar erros alheios numa perspectiva moralista, inconsequente e, por que não dizer, cínica. A intenção é tentar contribuir para uma tomada de consciência por parte dos agentes do campo para as implicações de suas ações na dinâmica social, de modo a superar as frequentes análises parciais (e comumente de teor beneficente) que mais mantêm do que enfrentam tais estratégias. Para tanto, recorremos ao referencial teórico gramsciano no que concerne às categorias de sociedade civil e de hegemonia, somando-se a elas a de estratégias contrahegemônicas, na acepção de WILLIAMS (2005), levando-se em consideração, no caso destas últimas, as ressalvas de DORE \& SOUZA (2018).

\section{Hegemonia}

A categoria de hegemonia, elaborado por Antônio Gramsci e aplicável às sociedades capitalistas democráticas, consiste no objeto de disputa de sentidos no qual uma classe ou fração de classe se faz socialmente dominante por meio de mecanismos culturais para editar e inculcar um senso comum, constantemente renovado, que se estabelece na experiência cotidiana como um sistema que tenciona tornar "natural" concepções historicamente construídas. A questão central neste estudo é mostrar que, embora o design visual possa trabalhar em prol do exercício da hegemonia, e historicamente a isso tem se dedicado com entusiasmo, ele não está intrinsecamente ligado a tal.

A disputa pela hegemonia se dá no âmbito do que Gramsci chama de sociedade civil expressão herdada do liberalismo clássico que é reelaborada pelo filósofo italiano, sendo

[...] formada por múltiplas organizações sociais de caráter cultural, educativo e religioso, mas também político e, inclusive, econômico. Por seu intermédio, difundemse a ideologia, o consenso e a direção moral e intelectual do conjunto social. Nela se forma a vontade coletiva, se articula a estrutura material da cultura e se organiza o consentimento e a adesão das classes dominadas (ACANDA, 2006:175).

Na construção teórica gramsciana, a sociedade civil se diferencia da sociedade política porque esta segunda consiste no aparelho de estado propriamente dito - ou seja, as instituições de estado e, por decorrência, todas aquelas capazes do uso lícito da coerção para a manutenção do poder. A violência é a forma mais radical da coerção, e por isso ela é monopólio da sociedade política. Desta forma, no que concerne à manutenção do poder, é comum definir-se sociedade política como o âmbito da coerção, enquanto sociedade civil é o âmbito do convencimento, da obtenção de consenso. No entanto, na construção gramsciana, ambas - sociedade política e sociedade civil - formam o estado (ou estado em sentido amplo), e esta é uma das suas contribuições mais originais para a teoria política. Ao incluir a sociedade civil no estado, ele o concebe então como um palco de forças políticas de coação e convencimento em disputa permanente pela manutenção da dominação. 
Ou seja: a disputa política não ocorre, por exemplo, apenas em função da realização de eleições (mecanismo da sociedade política), mas também - e principalmente (e aí está a chave para a compreensão da contribuição do autor) - no âmbito da sociedade civil: nos valores diariamente propagados nas escolas, na televisão, nas pregações de padres e pastores, nas peças de publicidade, nos comentários de locutores de rádio e que, não havendo instâncias com capital suficiente (seja econômico, cultural, social e/ou simbólico, conforme as categorias de BOURDIEU (1996)) para contraposição, são propagados nas conversas travadas nas filas, nas salas de espera, nas feiras, nos ônibus. Ou seja: são legitimadas por meio daquilo que Gramsci denomina aparelhos privados de hegemonia (categoria que não deve ser confundida com a dos aparelhos ideológicos de estado, de Althusser, apesar da semelhança da nomenclatura).

A hegemonia é "um processo no qual uma classe hegemoniza, na medida em que representa interesses que também reconhecem como seus as classes subalternas" (MARTÍN-BARBERO, 2006:112, grifo nosso). Como observa o autor espanhol radicado na Colômbia, a hegemonia não é sólida e estável; ela se faz, desfaz e refaz, incessantemente, na elaboração e na apropriação de sentidos, porque a permanência e difusão da ideologia é um processo de convencimento contínuo. De acordo com Luciano Gruppi (1978:90), uma classe social "dominante no plano econômico, e, por isso, também no político, difunde uma determinada concepção de mundo" reforçada pelo apoio de "um bloco histórico de forças sociais e de superestruturas políticas" e daí obtém a hegemonização das demais classes sociais. "A hegemonia [...] não é apenas política, mas é também um fato cultural, moral, de concepção de mundo" (GRUPPI, 1978:73). O sociólogo galês Raymond Williams, considerado um dos pioneiros da abordagem dos estudos culturais, defende o uso desta noção, em detrimento da de ideologia - embora ambas se articulem - por considerá-la mais dinâmica:

[...] hegemonia supõe a existência de algo verdadeiramente total, que não é meramente secundário ou superestrutural, como na acepção fraca de ideologia, mas que é vivido numa tal profundidade e satura a sociedade de tal maneira que, como Gramsci coloca, constitui a substância e o limite do senso comum para muitas pessoas sob sua influência e corresponde à realidade da experiência social muito mais claramente do que quaisquer noções derivadas da fórmula [atribuída ao marxismo clássico] de base e superestrutura (WILLIAMS, 2005:216).

A capacidade da classe dominante de obter e manter a hegemonia depende, como sublinha o filósofo cubano Jorge Luís Acanda (2006:177-178), de como é produzido e organizado o consenso e a direção política, intelectual e moral para as demais classes, embora também dependa, para sua conservação, do controle que mantém sobre os meios de produção e os instrumentos de repressão. A hegemonia é vista, nesse sentido, como direção ideológica e política numa combinação do poder de consenso e de coerção, embora este em menor ênfase. Tal ocorre por questões estratégicas para a conservação da dominação, dada a importância "dos mecanismos de produção de hábitos de comportamento, valores e modos de pensar [...] para a estruturação do poder nas sociedades modernas" (idem, 2006:174). Como reforça Denys Cuche, numa abordagem antropológica que se aproxima muito daquela de Gramsci:

Uma cultura dominante não pode se impor totalmente a uma cultura dominada como um grupo pode fazê-lo em relação a um outro grupo mais fraco. A dominação cultural nunca é total e definitivamente garantida e, por esta razão, ela deve sempre ser acompanhada de um trabalho para inculcar esta dominação cujos efeitos não são jamais unívocos; eles são às vezes [...] contrários às expectativas dos dominantes, pois sofrer a dominação não significa necessariamente aceitá-la (CUCHE, 1999:146).

No mesmo caminho, WILLIAMS (2005:216) observa que a hegemonia não é absorvida e vivida de maneira uniforme. As estruturas têm de ser permanentemente renovadas e justificadas e, ao mesmo tempo, "elas podem ser continuamente desafiadas e em certos aspectos modificadas". Por isso, a cultura dominante está sempre atenta a qualquer outra manifestação cultural que se apresente em ascensão: a hegemonia tende a absorver as culturas de resistência e contestação, aplainando as contradições e tornando tais manifestações mais um produto para a especulação mercadológica. 
[...] A habilidade do grupo que detém o poder não reside em tentar impedir as manifestações dessa diversidade, e sim em cooptá-las para seu projeto global de construção da trama social. É a isso que Gramsci chama de hegemonia (ACANDA, 2006:181)

Assim, a hegemonia se dá num processo de incorporação (WLLIAMS, 2005:217) e dele a cultura dominante depende e é dentro dele que essa cultura deve ser compreendida. Para que esse processo obtenha sucesso é preciso legitimá-lo socialmente, e para isso a classe que detém o domínio conta com intelectuais para conduzi-lo, bem como veículos de produção, formalização e difusão de discursos, frequentemente com aparência crítica, mas que naturalizam a dominação como inexorável. Esse mecanismo é particularmente visível em boa parte da produção acadêmica que, na virada do século, buscou problematizar, no dizer de CHAUÍ (2008:61), "a condição pós-moderna, isto é, a existência social e cultural sob a economia neoliberal", sem jamais ajustar tal problemática a estes termos. Tendo foco na aplicação da teoria do campo de Bourdieu ao caso brasileiro, Jessé Souza (2017) destaca que a classe dominante "comprou uma inteligência" para formular teorias precisas, no intuito de obter o controle social, e que tal compra "não se dá apenas nem principalmente com dinheiro: são os mecanismos de consagração de um autor e de uma ideia, seguindo aparentemente todas as regras específicas do campo cientifico" (SOUZA, 2017:167). Assim,

Não basta construir a universidade mais importante e de mais prestígio [...]. É necessário ter os jornais também nas mãos da elite para reverberar as teorias falsamente críticas [...]. É preciso ter as editoras de maior nome e influência e o acesso aos financiamentos de pesquisa, aos prêmios, honrarias e mecanismos de consagração intelectual. Assim, é possível usar a posição de proprietária dos meios de produção material para se apropriar dos meios simbólicos de produção e reprodução da sociedade (SOUZA, 2017:167).

\section{Design visual e hegemonia}

O design visual tem sofisticadas ferramentas projetuais que lhe garantem uma grande capacidade de denotar discursos, um forte poder comunicacional que se torna eficaz na disseminação (e conservação) de hábitos, valores e, mesmo, concepções de mundo:

O design é um discurso, e como tal espelha a condição cultural na qual e para a qual foi concebido ao mesmo tempo em que contribui para produzir, realimentar ou transformar esta mesma condição cultural [...]. [Ele é] uma prática comunicativa historicamente determinada e denotador de textualidades próprias da contemporaneidade e de suas relações de poder (VILLAS-BOAS, 2009:21 - grifos do autor).

Amparados pelo arcabouço teórico desenvolvido até aqui, chegamos à seguinte constatação:

Que o design visual integra a dinâmica cultural não há qualquer dúvida - isto é um fato; não uma questão. E é um fato nem que seja porque ele atua diretamente na alteração dos sentidos atribuídos aos objetos, especialmente naqueles transformados em mercadorias (ou seja, é ferramenta usual para a consecução do fetiche da mercadoria). Ou porque ele contribui para a hegemonia (ou, em menor escala, para posições contra-hegemônicas) por meio de suas próprias formas e pelas formas (e suas propriedades) selecionadas como constitutivas dos projetos (uma dada cor e não outra, uma dada tipografia e não outra), que realimenta (ou não) os sentidos hegemonicamente atribuídos a estas formas. Como exemplo rápido, as formas rosas para as meninas, com sua implicação para as concepções de gênero (VILLAS-BOAS, 2020:32-33). 
Assumindo tal perspectiva, desenvolver um projeto em design visual torna-se um desafio, um confronto, um combate entre os modos de fazer, significar e interpretar. É um enfrentamento ético numa inquietação estética. Torna-se um caminho incerto o da criação, no decorrer do qual o caminhante tem de se colocar em risco. Sobre este caminho trataremos mais à frente, pois o que importa ainda nesta altura é notar que nós, designers, vivemos diante de uma saturação de soluções acríticas e dadas sobretudo como funcionais - que fazem com que a atividade projetual não transforme, mas conserve; não imagine e crie, mas repita e reforce.

Philip Repp (1995:64) nota que, em nossa profissão - assim como na contemporaneidade como um todo - informação e tecnologia propagam-se extensivamente, resultando em manuais, códigos, dados, gráficos e outras "exibições tecnológicas". É preciso, então (REPP, 1995:63) "abandonar a tentativa de espelhar a máquina", ser receptivo, porque na pressa de analisar informações, procuramos pré-empacotá-las em numerosas embalagens, perdendo diversidade, riqueza e singularidade. O autor fala da necessidade de vocabulários mais pessoais em design, de uma visão dinâmica, da compreensão de que as relações podem nos aproximar mais da verdade sobre coisas do que as próprias coisas.

Muitas vezes - ou, talvez, na maioria delas - não nos damos conta do caráter ideológico de nossos projetos, e a própria formação profissional - e antes dela, a própria educação básica - atua como aparelho de hegemonia no sentido de extirpar qualquer co-relação mais crítica com a dinâmica social. Sem fazer qualquer questão de esconder seu inconformismo, MATIAS (2014:182) identifica na teoria do design uma "incapacidade de apreender qualquer rasgo de contradição na realidade social. Quando esta surge, é tratada como mera "externalidade"”.

Assim, aplicando o raciocínio do mesmo autor (idem, p.213), embora ele priorize a análise do design de produto, e não a do design visual, as classes sociais aparecem diluídas no conceito de mercado, seus membros são reduzidos a consumidores e se distinguem apenas como público-alvo: é a lógica do despertar (um eufemismo para criar) desejos para o consumo. Em sua obra, Matias faz uma exaustiva revisão bibliográfica da qual emergem concepções, contradições e análises críticas da inserção do design na lógica social com as quais a maioria de nós jamais teve qualquer contato. Assim, não é à toa que resumamos a Bauhaus às ideias de Gropius e Moholy-Nagy (às vezes, também às de Johannes Itten...) e a Escola de Ulm a um racionalismo quase folclórico.

$\mathrm{O}$ autor aponta "o preconceito e a resistência no meio do design, em relação a todo conhecimento que não parece imediatamente 'aplicável' ao desenvolvimento de produtos. Trata-se de um fenômeno que parte de uma visão estreita da noção de prática" (MATIAS, 2014:39) - e é à discussão sobre esta noção que nos dedicaremos no próximo item deste artigo. Antes, no entanto, cabe observar que a prática projetual em design embute nela mesma, na metodologia legitimada pelo campo, uma postura crítica frente à dinâmica social. É o que aponta a formulação da categoria de autonomia projetual de VILLAS-BOAS (2009):

O conceito de autonomia projetual parte de uma interpretação - e uma operacionalização - política dos próprios fundamentos da metodologia do design: tal como o projeto deve ser elaborado a partir dos requisitos e das restrições apresentadas pela situação de projeto, o próprio design gráfico deve ser praticado, conceituado e desenvolvido a partir de sua inserção histórica (ou seja: concreta, efetiva, inserida nas relações sociais tais como elas se apresentam). Isto não significa conformar-se passivamente com as condições históricas tais como elas se apresentam, mas uma tomada de posição: assumir um enfrentamento concreto e consequente destas condições.

[...] Tomada como princípio, o conceito de autonomia projetual tem uma aplicação política, diretamente ligada à busca pela autonomização do campo do design gráfico. Tal significa dizer que, aplicado o conceito como princípio geral do design gráfico como campo, este passa a ser concebido como intrinsecamente ligado às relações sociais nas quais se desenvolve e à sua experiência histórica (VILLAS-BOAS, 2009:84).

Neste raciocínio, mostram-se falaciosas as teses amplamente difundidas de que o design visual é ou tende a ser necessariamente uma atividade ligada à conservação e à reprodução das relações 
sociais tais como se apresentam. Justamente ao contrário, está na sua própria conformação ontológica, na própria metodologia que o legitima, a sua vocação para a emancipação. Exceto, evidentemente, quando a ideia de emancipação não está no horizonte - ou quando se atua justamente contra ela. Aí, sim, temos um efetivo desvio do design como prática social.

\section{Design e práxis}

A ideia de práxis embute justamente o sentido de que toda prática é, em si mesma, uma prática social - pois seria fantasioso conceber qualquer prática como independente das relações sociais que necessariamente a geraram e das implicações sociais que, em maior ou menor grau, ela efetivamente gera - e nisso se inclui a prática profissional. Compreender como isto se dá historicamente (ou seja, concretamente, na própria prática) é tarefa da filosofia da práxis.

A expressão filosofia da práxis frequentemente utilizada por Gramsci em seus 32 Cadernos produzidos na prisão é interpretada também como uma sinonímia camuflada para escapar de eventuais ações repressivas do fascismo de Mussolini: filosofia da práxis em substituição a materialismo dialético, de Marx e Engels. No entanto, mais do que uma simples substituição de termos, a filosofia da práxis "não é tanto um sinônimo, mas uma verdadeira revisão e interpretação do materialismo dialético" (DAINOTTO, 2017:300), especialmente frente à obra Teoria do materialismo histórico. Manual popular de sociologia marxista de Nikolai Bukharin, patrocinado e amplamente divulgado pelo stalinismo. Gramsci vê na disseminação da interpretação de Bukharin uma vulgarização reducionista da teoria marxista, eivada pelo positivismo e pelo materialismo que ele chama de filosófico, metafísico ou mecânico (isto é, não dialético):

Para a filosofia da práxis, a "matéria" não deve ser entendida nem no significado que resulta das ciências naturais [...] nem nos significados que resultam das diversas metafísicas materialistas [...]. A matéria, portanto, não deve ser considerada como tal, mas como social e historicamente organizada pela produção e, desta forma, a ciência natural deve ser considerada essencialmente como uma categoria histórica, uma relação humana (GRAMSCI, 1977:1442, apud DAINOTTO, 2017:301).

A articulação permanente entre teoria e prática proposta por Gramsci se coaduna com a perspectiva de se opor à separação entre sujeito e objeto, própria da filosofia até então dominante. Em vez disso, o filósofo italiano propõe, a partir de Marx, que a determinação é dialeticamente recíproca entre ambos, numa relação intrínseca também com a dinâmica social, as relações de trabalho e o sistema de produção.

$\mathrm{Na}$ realização da práxis, a gênese do ser social se dá na medida em que o indivíduo adquire conhecimento, portanto, o ser que produz sua vida material também produz sua subjetividade, ao se apropriar das múltiplas relações do mundo subjetivo e objetivo. No qual, além de possuírem novos conhecimentos e habilidades, os indivíduos possuem o que objetivaram para a construção de um próximo objeto, mais elaborado, que possua novas qualidades, atendendo melhor as suas necessidades a partir de novas carências que surgirão, o que levará esse indivíduo a novas objetivações (GUERRA \& FERREIRA, 2016:05).

$\mathrm{Ou}$, nas palavras dos próprios autores originais desta perspectiva, numa passagem famosa,

A produção de ideias, de representações, da consciência, está, em princípio, imediatamente entrelaçada com a atividade material e com o intercâmbio material dos homens, com a linguagem da vida real. [...] não se parte daquilo que os homens dizem, imaginam ou representam, tampouco dos homens pensados, imaginados e representados para, a partir daí, chegar aos homens de carne e osso [...]. Não é a consciência que determina a vida, mas a vida que determina a consciência (MARX \& ENGELS, 2007:93-94). 
Assim, conforme GUERRA \& FERREIRA (2016:05), tudo que é criado pelo ser humano é um "constructo social", pois o ser social é transferido para o produto que desenvolve a partir da sua atividade intelectual e manual (por sua vez, condicionada pela produção intelectual e manual de outrem e que está contida na sua realidade concreta - e por isso mesmo ele é um ser social). Desse modo, todo objeto, todo signo, todo significado, é construído socialmente e tem uma função social.

A existência não é somente "enriquecida" pela obra humana; na obra e na criação do homem é que se manifesta a realidade e, de certa forma, se realiza o acesso a ela. Portanto, a práxis na sua essência é a determinação da existência humana como elaboração da realidade. Ser que cria a realidade humano-social e compreende a realidade em sua totalidade (humana e não- humana). A práxis é ativa, mas é atividade que se produz historicamente, é unidade do homem e do mundo, da matéria e do espírito, de sujeito e objeto, do produto e da produtividade. (GUERRA \& FERREIRA, 2016:07).

FREITAS (2013), partindo do pensamento do filósofo Adolfo Sánchez Vázquez, em especial de sua Filosofia de la práxis (publicada originalmente em 1967 e sucessivamente revista até 2003), apresenta um diagrama no qual define graficamente as características principais da práxis sintetizada por ele. Aqui apresentamos uma adaptação deste diagrama aplicado ao design (fig. 1).

Ora, o que o diagrama apresenta não é viável para a maioria dos agentes do campo. Designers, assim como quaisquer outros indivíduos, precisam sobreviver, ser remunerados - e, na maioria dos casos, pretendem ser cada vez mais bem remunerados. Além disso, é a possibilidade do exercício da criação que move a maioria de nós; é para criar por meio de imagens que nos dedicamos a esta profissão. E, tanto para um caso como para o outro, dependemos do capital: é por meio do poder econômico (do patrão, do cliente) que temos a possibilidade de remuneração e de criação em condições satisfatórias (ou seja, em situações de projeto que nos possibilitem a produção daquilo que projetamos em condições de qualidade compatíveis com o que foi projetado e que, por sua vez, deve ser compatível com a situação de projeto).

Temos aí um impasse, cuja resolução mais simples não interessa aos objetivos deste estudo: esquecer todas as implicações sociais da atividade e seguir em frente, como não se houvesse amanhã e torcendo para que, antes desse amanhã chegar, a carreira tenha se encerrado com um grande acúmulo de bens e de projetos que contribuíram para a efetivação do amanhã previsto há muito: desigualdade extrema, extermínio em massa, hecatombe ambiental.

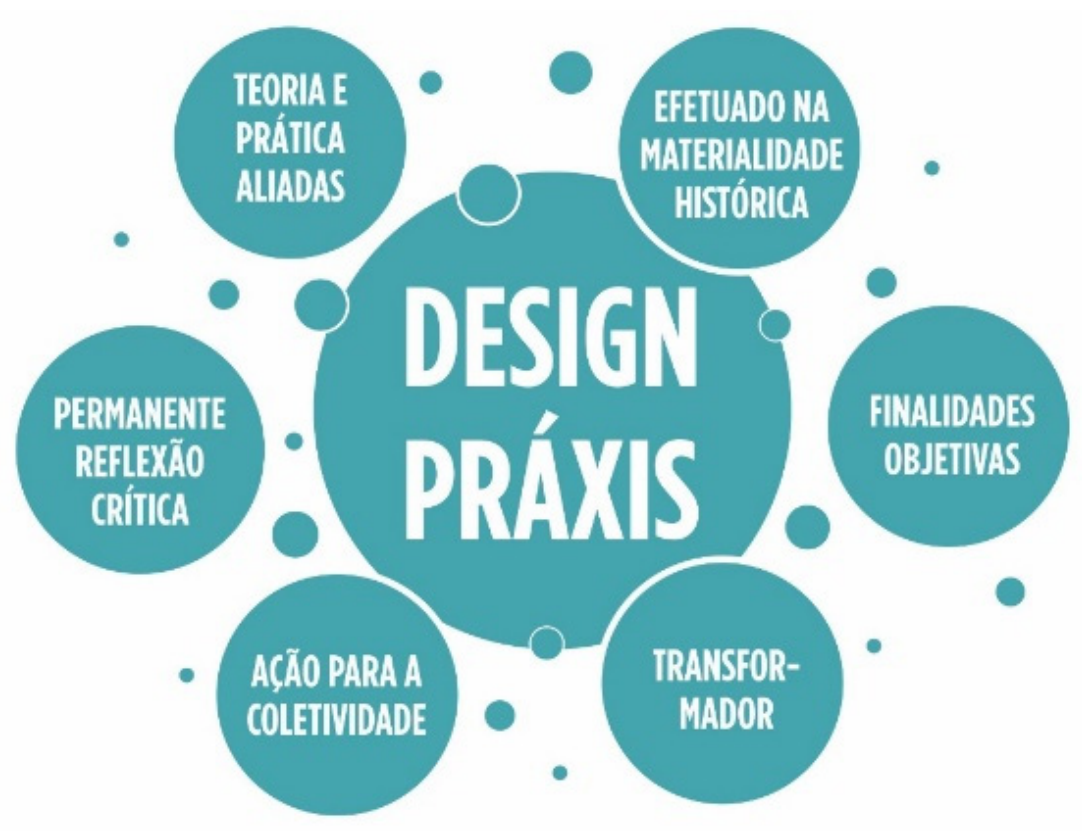

Figura 1 - A prática profissional do designer a partir da filosofia da práxis em Adolfo Sánchez Vázquez (adaptação nossa do diagrama presente em ALVES (2013:08)). 
Não é nosso intuito apresentar um receituário de como um designer deva atuar criticamente. Mas é oportuno pensar em algumas saídas para este impasse. Elas podem ser articuladas em ações dentro e fora do campo do design, mais incisivas ou mais sutis, imediatas ou de perfil mais teleológico quanto à sua ação contra-hegemônica.

Descartando aquela primeira alternativa, a que surge imediatamente se refere ao próprio exercício da cidadania, que se amplia para além do campo do design. E, na atual conjuntura, ele incide diretamente na própria sobrevivência do campo em moldes razoáveis de desenvolvimento e capacidade de geração de atividade criativa (o que, afinal, é o que nos move). Por isso, o exercício da cidadania, em seu aspecto mais político, é evidente para inviabilizar o projeto, em andamento, do retorno do país à condição de economia agro-exportadora.

Commodities não dependem de peças de design visual para serem promovidas e comercializadas. No setor industrial e de desenvolvimento tecnológico, em contrapartida, as transnacionais têm adotado estratégias globais de branding, no geral limitando as encomendas locais de design, feitas por suas subsidiárias, a adaptações de projetos exógenos. Exceto se nos conformarmos a ter como limite intransponível a identidade visual destinada a pequenos negócios, ser designer hoje no país significa assumir posturas políticas de resistência.

No entanto, hegemonia não é sinônimo de proeminência política no sentido partidário nem êxito nas disputas político-econômicas do dia a dia (embora elas possam representar avanços na disputa por hegemonia, na lógica do que Gramsci chama de guerra de posição). Qual seja porque o projeto agro-exportador tem conotações geopolíticas que transcendem em muito as atuais figuras exóticas que proliferam em nosso cenário, seu enfrentamento não tem como ser meramente pontual. Ele requer justamente uma postura crítica que incida no cerne da disputa ideológica de amplo espectro: é uma questão da esfera da hegemonia.

No interior do campo, esta postura crítica não se perfaz necessariamente pelo fomento a hostilidades cotidianas com o capital (ou seja, com o cliente ou com o patrão). Ela se dá justamente na consciência da forçosa necessidade da autonomia do campo (aqui, usamos autonomia na acepção de Bourdieu) e isso só tem como ocorrer a partir da crítica aos próprios fundamentos sobre os quais ele se formou e se conserva - e por isso, um pouco mais à frente, abordaremos o coletivo Design Ativista.

Um exemplo simples, que talvez soe inusitado. É comum, seja nas conversas entre nós, nas aulas de vários professores ou em artigos acadêmicos sobre tipografia, o emprego da expressão fontes populares, no sentido de fontes muito usadas. Ora, popular tem para nós, brasileiros, a acepção de algo ligado ao povo e este povo não se refere à população como um todo, mas especificamente às classes de baixa renda (exatamente porque elas são majoritárias na sociedade brasileira). Então, o que queremos dizer com a expressão fontes populares é que os pobres preferem a Times New Roman à Baskerville? Evidentemente que não: afora o anglicismo que denota nossa consciência colonial (a adoção da expressão só se justifica como uma prática que não se configura em práxis, já que não tem qualquer coerência com nossa realidade concreta ao se originar do popular fonts veiculado nos sites norte-americanos), aquilo que lhe dá sentido é a exclusão, de nosso universo simbólico, da parte majoritária da população. São fontes "populares" porque o que conta mesmo somos nós: brancos e de classe média. O resto não existe. Isto é hegemonia: quando a dominação se dá de forma tão incorporada que sequer a percebemos - e a reproduzimos sem perceber.

\section{Dois acertos teóricos}

Diferentemente do tratamento invariavelmente dado pela historiografia do design produzida ou legitimada no interior de nosso campo, a associação do design visual a práticas que, por definição, se contrapõem à hegemonia não são pontuais na história do design; não constituem exceções, mas sim uma constante. Na dissertação de mestrado da qual este artigo se origina, são listados e abordados sete dentre estes momentos mais expressivos, num levantamento que está muito longe de ser extensivo: entre eles, o construtivismo e o produtivismo na Rússia revolucionária, o cartazismo cubano, o tropicalismo, a luta pelos direitos civis da população negra dos EUA e o movimento operárioestudantil de maio de 1968 na França. E, sem muito esforço, o leitor ou a leitora provavelmente se lembrará de pelo menos outros três exemplos que se somariam a estes. Neste artigo, damos relevo ao coletivo Design Ativista, também enfocado na dissertação, dada a sua contemporaneidade, à singularidade de sua expressão visceralmente baseada na própria atividade do design (e que 
enunciadamente reivindica sua inscrição no interior do campo) e à novidade de sua forma de organização.

Neste ponto, por conta de algum rigor teórico, cabe abordar rapidamente duas questões. A primeira se refere à aplicação da teoria da hegemonia à interpretação do construtivismo e do produtivismo. A hegemonia foi identificada por Gramsci como recurso de conquista e manutenção da dominação em sociedades capitalistas desenvolvidas e cujos aparelhos de estado, ao menos nominalmente, se pautam pelos ditames da democracia liberal. Evidentemente, tais condições não se apresentavam na Rússia czarista nem no imediato período pós-revolucionário, quando emergem e se desenvolvem estes dois movimentos.

No entanto, ao menos naquele momento preciso, a construção discursiva dos bolcheviques se pautava pela revolução proletária mundial, internacionalizada, e não com vistas exclusivamente à conjuntura russa: o "homem novo" a ser construído não seria russo, mas constituído por uma nova direção intelectual e moral (para usar os termos precisos de Gramsci) da sociedade humana como um todo, dirigida pelos trabalhadores, numa perspectiva internacionalista (evidentemente, quase eurocêntrica, dada a época). O discurso construtivista e produtivista se pauta por estes mesmos termos. Por isso, podem ser interpretados, não perante à dinâmica social russa, mas frente às sociedades capitalistas mais avançadas de então, como contra-hegemônicos.

Desta feita, seguimos para o segundo ponto que necessita de esclarecimento quanto a seu rigor teórico: uma controvérsia justamente com relação à categoria de contra-hegemonia - ainda que não aprofundemos este tema porque, tratando-se de uma discussão complexa no âmbito da teoria política, foge ao nosso escopo e perícia para fundamentação. Em recente artigo, DORE \& SOUZA (2018) são taxativos ao afirmarem que a noção de contra-hegemonia - amplamente adotada na enorme bibliografia produzida em torno da obra do pensador italiano, tanto no exterior quanto no Brasil - não pertence ao quadro teórico elaborado por Gramsci e, mais grave, seria até mesmo incoerente com ele. De fato, o monumental Dicionário Gramsciano, organizado por Guido Liguori e Pasquale Voza e publicado originalmente na Itália em 2009 (no Brasil, em 2017, pela Boitempo Editorial) não contém contra-hegemonia. A obra compila (e mapeia detalhadamente nos originais escritos na prisão) os temas abordados por Gramsci, organizados em quase oitocentos verbetes nos quais um sem número de especialistas de países diversos dissertam sobre cada um deles.

Conforme Dore \& Souza, a noção de contra-hegemonia teria origem no célebre artigo de Raymond Williams sobre as categorias de base e superestrutura, publicado originalmente em 1973 (WILLIAMS, 2005). A partir daí, teria sido assumida, de modo equivocado, por quase toda a bibliografia posteriormente produzida sobre o arcabouço teórico gramsciano como efetivamente presente nele. Diante disso, por cautela, não utilizamos neste artigo o termo contra-hegemonia, embora, paradoxalmente, estejamos usando contra-hegemônicos e seus derivados, mantendo em suspenso a questão numa espécie de solução de compromisso.

\section{Design Ativista e Mídia Ninja}

Uma amostra de práxis que atua criticamente tanto fora do campo do design como no interior dele é a experiência do Design Ativista. A hashtag \#designativista é um canal virtual de difusão de conteúdo político, no qual uma diversidade de designers e artistas publica seus trabalhos. Ela se baseia em postagens no Instagram, rede social na internet dedicada a compartilhamento de fotos e vídeos, mas seu material também é reproduzido em outras redes sociais (especialmente no Twitter), inclusive com material produzido especificamente para difusão nelas. Por meio da hashtag, é distribuído material gráfico digital que discute questões contemporâneas, especialmente brasileiras, com enfoque crítico e de defesa da cidadania, com particular atenção aos direitos dos grupos discriminados.

No Instagram, a hashtag foi proposta e é continuamente realimentada a partir do perfil @designativista, administrado por membros do coletivo Design Ativista Para Quem Não Aguenta Mais (ou, simplesmente, Design Ativista). O coletivo, por sua vez, foi idealizado pela Mídia Ninja e pela Ideafixa, sobre as quais trataremos um pouco mais à frente. Enquanto o Design Ativista atua fundamentalmente no Instagram, a Mídia Ninja parece ser a principal impulsionadora da difusão do material no Twitter, conforme nossos acessos àquela rede em junho e julho de 2020.

É interessante notar que, na forma de uma hashtag que aglutina seus membros, se trata de um movimento social diverso. É assim não apenas por que se singulariza por estar fundado na prática do 
design, mas porque suas ações são por definição descentralizadas, pela lógica mesma das redes: a rigor, qualquer um pode fazer um post usando a hashtag \#designativista, sem que haja um monopólio de controle tanto desta produção quanto de sua difusão.

A hashtag é uma palavra ou combinação de palavras que, antecedida pelo sinal de tralha (\#), é usada em postagens no Instagram (e, igualmente, em outras redes sociais) como um indexador para recuperação de dados: ao inseri-la na ferramenta de busca daquela rede, o usuário acessa uma compilação de postagens que têm em comum o uso daquele indexador. As hashtags podem ser mais duradouras ou muito efêmeras, dependendo do interesse dos usuários da rede.

Evidentemente, se um usuário utilizar uma hashtag de maneira incoerente com sua postagem, a difusão desta tenderá a não ocorrer, pois os demais usuários não a compartilharão. E, dependendo da gravidade desta incoerência, o autor da postagem poderá até mesmo ser "bloqueado" ou "cancelado" pelos usuários que têm interesse naquele tema (ou seja, deixarão voluntariamente de receber novas postagens que ele vier a fazer). Assim, ele tende a ser gradativamente excluído do universo de usuários que compartilham aquele determinado interesse.

Desta forma, aparentemente a gerência sobre uma hashtag não se dá de maneira vertical - ou seja, por alguma instância que controle sua veiculação - mas horizontal: pelos próprios usuários mobilizados pelo assunto da hashtag. O dado mais relevante que rompe com a plenitude democrática do processo é o fato de que as redes sociais têm donos: cada empresa detentora tem controle sobre a veiculação das postagens, já que por definição administra os dados a serem compartilhados. Não há mecanismos de controle social que garantam que ela não exerça esta prerrogativa de acordo com seus interesses.

A Mídia Ninja se apresenta como uma rede de comunicação independente, também formulada para o ambiente da internet, que mantém uma lógica colaborativa de trabalho (MÍDIA NINJA, 2019a). Ela é mantida fundamentalmente em sistema de voluntariado, contando ainda com a infraestrutura logística da rede Fora do Eixo (voltada para a estruturação, logística e disseminação de sistemas de comunicação no âmbito das organizações da sociedade civil) e com financiamento de instituições internacionais voltadas para iniciativas comunicacionais ligadas a questões socioambientais e culturais (MÍDIA NINJA, 2020).

O coletivo atua na contramão da grande mídia, registrando especialmente ações dos movimentos sociais em áudios, fotos e principalmente vídeos que são difundidos pelos usuários das redes sociais. Ele foi criada em 2013 e ganhou notoriedade por transmitir ao vivo, "de dentro", os protestos ocorridos naquele ano, conhecidos por "Jornadas de junho". Destacou-se também no período do impeachment, em 2016, nas eleições de 2018 e nos recorrentes protestos contra as políticas públicas do atual governo. A Mídia Ninja é hoje um agente decisivo na difusão de uma perspectiva crítica com relação ao que é difundido pelas grandes empresas de mídia.
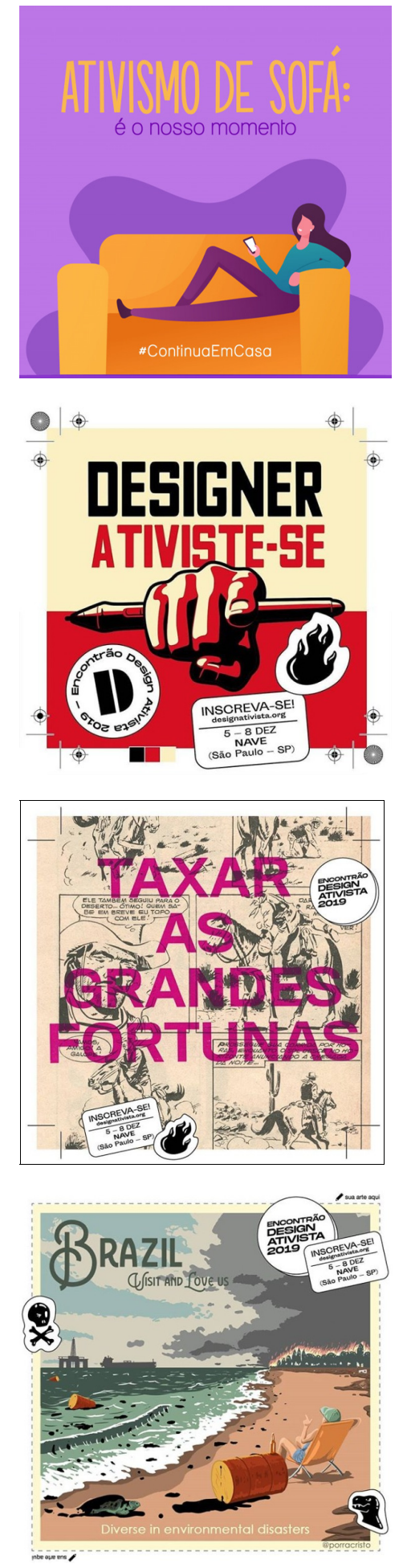

Figura 2 (no alto): post que associa o isolamento social em função da pandemia da covid-19 a práticas de ativismo virtual, de autoria de@drielle_fulco.

Figuras 3 a 5: divulgação de encontros presenciais do Design Ativista, veiculadas no Instagram ( @ crisvector, @maiconneryestudio e (a) porracristo). 
A IdeaFixa é também responsável por esse projeto de mobilizações em torno da prática do design como ativismo. Reúne uma plataforma digital, na qual compartilha conteúdos e notícias; administra uma casa de eventos e trabalho coletivo (em São Paulo, no bairro de Vila Mariana), com debates e oficinas. Além disso, oferece serviços de design visual, de cenografia, animação e fotografia (IDEAFIXA, 2020).

Além da atuação nas redes sociais, esses coletivos se reúnem periodicamente, em encontros presenciais ou por meios digitais, para discussões conjuntas entre designers (e também estudantes da área, artistas e demais interessados na atuação em comunicação) sobre a utilização do design para a transformação social, que também são divulgados em peças gráficas veiculadas sob a hashtag (figuras 3 a 5). Em seu site, a Mídia NINJA apresenta assim a iniciativa:

O design é uma ferramenta importante demais pra ficar só na mão das grandes corporações. Começamos como uma pequena comunidade, reunindo quem não aguentava mais ver tanta coisa errada sem poder fazer nada. A partir da primeira convocatória da Mídia NINJA e da IdeaFixa, crescemos e nos tornamos milhares de profissionais, estudantes e amantes do design conectadas e conectados, botando a mão na massa pra transformar a realidade, em contato com movimentos e coletivos. Um verdadeiro levante criativo! (MÍDIA NINJA, 2019b).

Em 2019, em 24 de julho, a hashtag \#designativista estava contando com 10.998 publicações no Instagram (levantamento realizado às 22:05 daquele dia). No dia seguinte (a 1:12 daquela madrugada), o perfil @designativista havia realizado 1.086 publicações e contava com 122 mil seguidores. Na rede social Facebook, o grupo Design Ativista, criado em 14 de junho de 2018, computava 1.794 membros, 63 deles inscritos apenas nos trinta dias anteriores. Nesta rede, o número de publicações é bem menor: 94 . $\mathrm{Na}$ página, o grupo se declara "dedicado ao recrutamento de designers, ilustradores, artistas, redatores, roteiristas, videomakers, desenvolvedores e demais interessados a usar seu tempo e talento para o que importa" (DESIGN ATIVISTA, 2019a).

$\mathrm{O}$ apelo à postura crítica individual para a realização de ações concretas também está na página do perfil @designativista no Instagram: "O design a favor do que você acredita. Crie e use a tag \#DesignAtivista, seu trabalho é para o mundo". Ou seja, um modo de mobilizar designers a criar de um modo engajado e compartilhar num canal comum se relacionando com questões como identidade, violência, preconceito, representatividade, diversidade cultural e justiça social (figuras 6 a 9).

Assim como os encontros presenciais, já ocorridos em São Paulo e no Rio de Janeiro, esse coletivo de designers promove outras ações diretas fora do mundo virtual. Nas manifestações de 15 de maio de 2019 - o conhecido "15M", em resposta a cortes de verbas de universidades e de institutos federais de ensino básico, técnico e tecnológico -, o Design Ativista disponibilizou arquivos
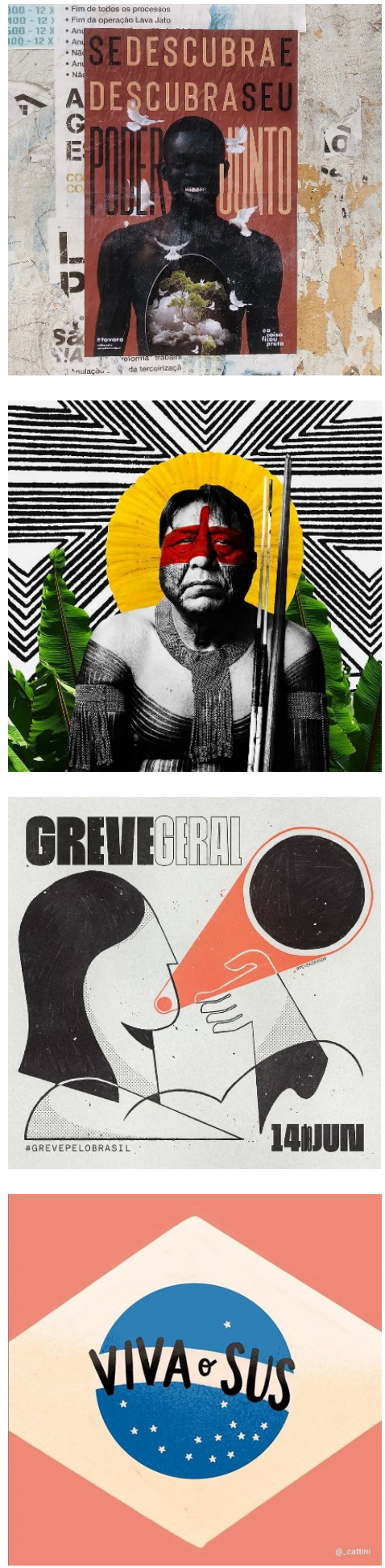

Figuras 6 a 9 - Lutas identitárias e de maior abrangência em posts de (a) acoisaficoupreta, @moraismavi,@peveazevedo e @_cattini. Aqui, como em todas as demais legendas, os autores estão indicados tal como se identificam em seus perfis na rede social Instagram, em ordem semelhante à disposição das imagens (de cima para baixo). 
com layouts de cartazes para serem impressos e usados por manifestantes (DESIGN ATIVISTA, 2019b). Foi inclusive veiculada no período uma hashtag específica conclamando outros designers para a criação de cartazes em torno das pautas em questão.

As postagens da hashtag \#designativista no Instagram, onde se encontram em maior número, têm predominantemente formato quadrado, que é a proporção padrão desta rede social. As que saem desse formato são ou destinadas a outras redes sociais ou as que buscam representações mais singulares. Aparecem também de forma recorrente imagens com simulações digitais de aplicações de cartazes sobre paredes, numa associação do digital com o impresso e com a força simbólica, ainda persistente, daquela mídia mais tradicional.

Em geral, os posts do Design Ativista - o que não engloba todos os trabalhos veiculados sob a hashtag \#designativista combinam ilustração e texto, mas há o uso protagônico da tipografia, para a qual geralmente são escolhidas fontes que procuram reforçar o sentido das mensagens, num claro objetivo de viabilizar uma comunicação direta e sem ambiguidades. Esta opção prioritária revela, mais uma vez, a ligação intrínseca da iniciativa com o ambiente digital, dado o rápido fluxo de informações e da absorção delas no ambiente da internet. No entanto, é comum que os projetos, mesmo sendo digitais, e em geral sem previsão de impressão, remetam a técnicas artesanais e adotem uma linguagem gráfica que faz alusão às técnicas tradicionalmente usadas em protestos de rua, como o stencil e a serigrafia, além de menções às técnicas e aos efeitos de impressão da gravura e do processo offset.

A variedade de técnicas de composição e estilos gráficos é grande, e vai de fotomontagens, quadrinhos e caricaturas até a linguagem computacional de primeira geração. Também lançam mão de visualidades próprias de manifestações e movimentos culturais diversos, como a poesia concreta, a pop art e o cordel, além de citações e releituras de obras consagradas pela história da arte. Por fim, fazem frequentemente referência a movimentos sociais e artísticos contra-hegemônicos que usaram o design visual para difundir seus ideários - especialmente as vanguardas históricas e, evidentemente, o Maio de 68.

O pertencimento ao campo do design é reafirmado constantemente: trata-se de um movimento social de designers realizado por meio de práticas de design. Esta frequência talvez denote a percepção crítica de que o próprio campo não legitima o que é realizado fora de certos padrões dados como profissionalmente legítimos (isto é, a serviço do capital e da sua reprodução), exceto quando legitimados por outros campos mais autônomos (o da história, o da sociologia, mas sobretudo o da arte).

Nesta perspectiva, se insere a homenagem ao centenário da Bauhaus, em 2019, que gerou uma exposição virtual (ou seja, on line) reunindo "cartazes virtuais" produzidos especialmente por cem designers brasileiros, mobilizados pelos coletivos citados. No entanto, a homenagem não foi concebida segundo os parâmetros legitimados no campo: seu discurso é claramente contra-hegemônico com relação a eles, embora verse sobre um dado consagrado por este mesmo campo e reivindique sua inscrição nele.
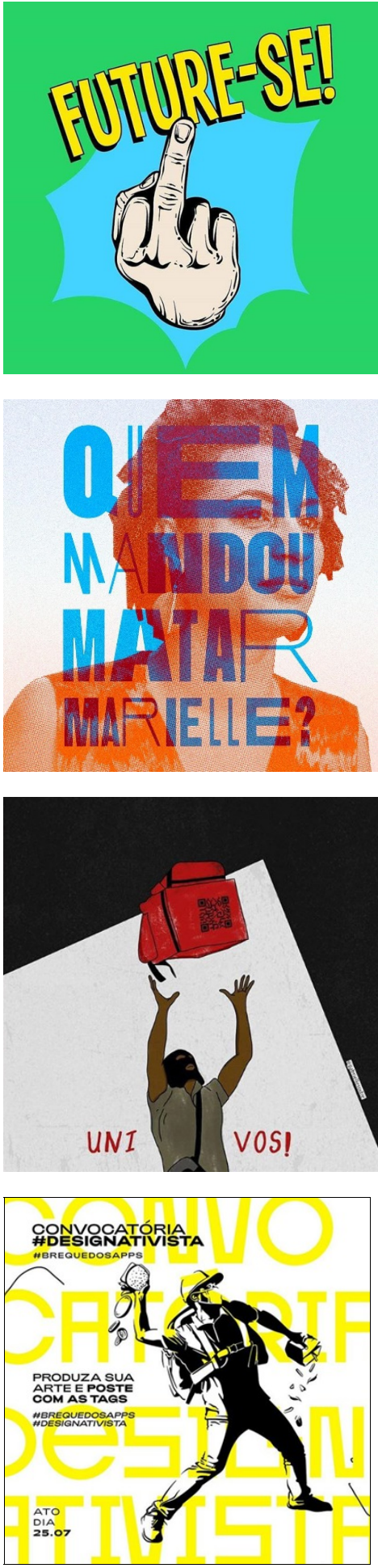

Figuras 10 a 13 - As postagens dialogam continuamente com as pautas dos movimentos sociais emancipatórios. No alto, posts de@gladsontarga e

@aviniciuss, seguidos por outro de@gabriellesodre e do próprio perfil@designativista, em apoio às greves dos entregadores precarizados por empresas de aplicativos. 
A perspectiva política de emancipação que orienta a homenagem é exposta no texto do manifesto que "abre" a exposição quando o usuário acessa sua página. A ênfase é dada aos objetivos de transformação social que a escola alemã teria representado, e não aos predicados tradicionalmente destacados em homenagens deste tipo (pioneirismo pedagógico, síntese formal, união de arte, artesanato e design), ainda que eles sejam mencionados no texto. Esta ênfase talvez indique uma provocativa valorização daquela que é considerada a terceira e última fase da Bauhaus, quando a escola foi dirigida por Hannes Meyer, e que é geralmente menosprezada - seja por um viés crítico ou por velada indiferença - pela historiografia legitimada pelo campo. Não à toa, foi o período de maior politização da instituição e, também não à toa, as propostas formuladas no período raramente são passíveis de análise e discussão: impera sobre elas quase um silêncio. Em contrapartida, a historiografia "oficial" quase resume toda a experiência da escola ao período em que foi dirigida por seu fundador, Walter Gropius. Não coincidentemente, foi esta a interpretação adotada como legítima pelo campo desde sua veiculação pela exposição realizada no Museu de Arte Moderna de Nova York, em 1938. A Bauhaus do Design Ativista não é a Bahaus do MoMA dos Rockefeller.

A postura crítica e de intervenção na realidade concreta, num ambiente contra-hegemônico convertido em práxis, também se insinua em outro trecho do manifesto. Ao afirmar a intenção de "desmistificar os paradigmas do obscurantismo cultural, educacional e democrático [...] nessa atmosfera emergente", o manifesto parece sugerir uma associação entre a configuração política que levou ao fechamento da escola - a ascensão do nazismo - ao atual cenário brasileiro, identificado por muitos como de tendência neofascista:

Como profissionais do design e das artes, reconhecemos toda importância do movimento [gerado pela Bauhaus] na consolidação da disciplina. $[\ldots]$

[...] Uma nova perspectiva de mundo veio à tona, graças às expressões e fundamentos da nova escola que aproximou a arte da produção industrial com métodos criativos e conceito educacional pluralista.

Cem anos depois, nós - entre formas, cores, texturas, tecnologia e princípios - prosseguimos, diligenciando desmistificar os paradigmas do obscurantismo cultural, educacional e democrático. Esse é o nosso propósito como emissários visuais nessa atmosfera emergente. À Bauhaus, nosso eterno agradecimento por projetar a construção crítica e deliberar influências e referências que hoje nos norteiam. (DESIGN ATIVISTA, 2019c)

O Design Ativista, bem como a Mídia Ninja e o IdeaFixa, se insere em um movimento global de uso da internet como ferramenta de disseminação da discussão política com viés emancipatório. As interconexões entre as mais distintas partes do planeta nunca foram tão rápidas, e nunca foi tão grande a quantidade de dados que se pode compartilhar. Grande parte das pessoas, em todo o mundo, tem
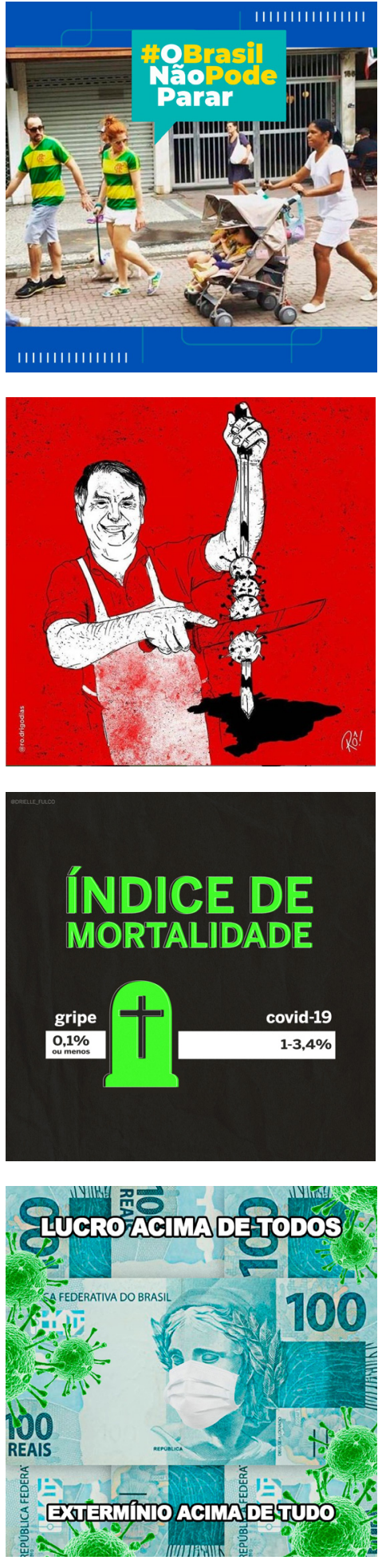

Figuras 14 a 17: Postagens críticas às políticas governamentais frente à pandemia da covid-19, de autoriade@henrique, @ro.drigodias,@driellefulco e, novamente,@henrique. 
acesso à rede virtual por meio de seus smartphones. Desse modo, assim como se torna mais fácil a manutenção da hegemonia por meio do alcance mundial proporcionado pela internet e suas novas plataformas, este mesmo alcance propicia a maior difusão dos discursos contra-hegemônicos (embora não necessariamente com a mesma eficácia em seus resultados imediatos).

\section{Considerações finais}

Embora parte considerável - talvez majoritária - da bibliografia corrente sobre design visual o associe à Revolução Industrial e, em decorrência disso, o sugira como umbilicalmente ligado à lógica do capital (que, efetivamente, foi o motor daquele processo), uma análise mais apurada pode demonstrar historicamente que, tal como o conhecemos, sua origem está justamente em movimentos de contrahegemonia, especialmente a partir das chamadas vanguardas históricas. É preciso lembrar que a Bauhaus, tomada em nossa tradição fundadora como marco referencial das práticas, concepções e parâmetros de legitimidade do campo, esteve vinculada às repercussões do construtivismo russo indiscutivelmente revolucionário - e ao De Stijl, que compartilhava, com ênfase, o ideário geral das vanguardas de levar a arte à vida (e há algum princípio mais contrário à lógica do capital?).

No Brasil, o movimento contrário e contemporâneo ao europeu - ou seja, o da publicidade norte-americana - foi muito mais determinante para o campo da publicidade do que para o do design visual, ainda que este, evidentemente, também tenha absorvido suas influências. Basta uma leitura nem tão pormenorizada dos artigos reunidos em BIERUT et al. (2010) de origem norte-americana na primeira metade do século XX para nos deixar perplexos diante da quase beligerância e descrédito que seus autores reservam para as "modernidades" europeias (às quais estamos mais do que habituados, dada à formação do campo no país).

No entanto, o próprio desenvolvimento das contradições sociais e o aprofundamento do desenvolvimento capitalista absorveu o design visual como uma de suas ferramentas decisivas para a manutenção da hegemonia, a ponto de, tal como referido anteriormente, a própria historiografia virá-lo de cabeça para baixo e tornar senso comum uma imaginária indissociabilidade entre design e capital, entre designers e aparelhos de hegemonia

O presente artigo procurou demonstrar como a atividade é efetivamente instrumentalizada com êxito - para este fim, de modo a que a compreensão deste processo possa contribuir para a tomada de consciência da falácia de tal indissociabilidade, sendo esta, em si mesma, uma construção que ao mesmo tempo realimenta e resulta da hegemonia. As atividades da \#designativista, tomadas como exemplo por sua contemporaneidade, ilustram uma das muitas iniciativas que, seguidamente tomadas como excentricidades ou "externalidades" ao campo (e sempre minimizadas), compõem a história do design visual e, no mais das vezes, são responsáveis por seus avanços.

\section{Visual design, hegemony and activism}

Abstract: This study is based on a master's thesis defended at the Federal University of Rio de Janeiro (UFRJ) and aims to correlate the social insertion of visual design to the Antonio Gramsci's theory of hegemony, particularly from the interpretations of ACANDA (2006) and WILLIAMS (2005). Also based on theoretical frameworks Bourdieu's field theory, the article defends a critical stance of the designer as a citizen and professional, inspired by MATIAS (2014), and seeks to show its viability, addressing the concrete experience of the Brazilian activist group Design Ativista, which works mainly through the internet.

Keywords: critical theory; Gramsci; praxis; field theory; \#designativista 


\section{Links}

DESIGN ATIVISTA, 2019a. https://www.facebook.com/groups/designativista/. Acesso em: 25 ju.I 2019.

DESIGN ATIVISTA, 2019b.

https://www.dropbox.com/sh/k5vjga13ay9i4r1/AAAHYYKCDRUI9Lwd04QvGzIKa?dl=0.

Acesso em: 25 jul. 2019)

DESIGN ATIVISTA, 2019c. https://www.bauhaus100anos.com.br/home Acesso em: 25 jul. 2019.

IDEAFIXA, 2020. http://www.ideafixa.com/. Acesso em: 27 jul. 2020.

MÍDIA NINJA, 2019a. http://midianinja.org/quem-somos/. Acesso em: 25 jul. 2019.

MÍDIA NINJA 2019b. http://midianinja.org/?s=design+ativista. Acesso em: 25 jul. 2019.

MÍDIA NINJA, 2020. https://midianinja.org/perguntas-frequentes/. Acesso em 27 jul. 2020.

\section{Referências bibliográficas}

ACANDA, Jorge Luís. Sociedade civil e hegemonia. Rio de Janeiro: UFRJ, 2006.

BIERUT, Michael; et al. Textos clássicos do design gráfico. São Paulo: Martins Fontes, 2010.

BOURDIEU, Pierre. Razões práticas. Sobre a teoria da ação. Campinas (SP): Papirus, 1996.

CHAUÍ, Marilena. Cultura e democracia. Crítica y Emancipación, (1): 53-76, junio 2008.

CUCHE, Denys. A noção de cultura nas ciências sociais. São Paulo: EDUSC, 1999.

DAINOTTO, Roberto. Filosofia da práxis [verbete]. In: LIGUORI, Guido; VOZA, Pasquale (org.). Dicionário Gramsciano, 1926-1937. São Paulo: Boitempo, 2017. p. 300-303.

DORE, Rosemary; SOUZA, Herbert Glauco de. Gramsci nunca mencionou o conceito de contrahegemonia. Cadernos de pesquisa, São Luís, v.25, n.3, jul./set. 2018.

FREITAS, Adenisia A. de. O Homem e a história na filosofia da práxis de Adolfo Sánchez Vázquez. In: CONGRESSO HISTÓRIA E LITERATURA: TEMPO E NARRATIVA, 19-22, 2013. Anais [...]. v.1, n.1, março 2013. Disponível em: https://www.anais.ueg.br/index.php/anais_congresso/article/view/1337. Acesso em 22/07/2020.

GUERRA, Agercicleiton Coelho; FERREIRA, Marcela Figueira. Marx e a filosofia: por uma Filosofia da Práxis. In: I JORNADA INTERNACIONAL DE ESTUDOS E PESQUISAS EM ANTONIO GRAMSCI, 23-25, 2016, Fortaleza. Anais eletrônicos [...]. Fortaleza: Grupo de Estudos e Pesquisas em Antonio Gramsci, 2017. Disponível em: http://www.ggramsci.faced.ufc.br/anais-i-gt1. Acesso em: 29 jul. 2019. MARTÍN-BARBERO, Jesús. Dos meios às mediações: comunicação, cultura e hegemonia. Rio de Janeiro: UFRJ, 2006.

MARX, Karl; ENGELS, Friedrich. A ideologia alemã. São Paulo: Boitempo, 2007.

MATIAS, Iraldo. Projeto e revolução. Florianópolis: Em Debate/UFSC, 2014.

NOBRE, Marcos. A teoria crítica. Rio de Janeiro: Zahar, 2004.

REPP, Philip C. Reflecting on a stone. Design Issues (The MIT Press), Cambridge, v. 11, no.3.

SOUZA, Jessé. A elite do atraso: da escravidão à Lava Jato, Leya. Rio de Janeiro: 2017.

VILLAS-BOAS, André. A complexidade da inserção do design visual na dinâmica da cultura, in: GRIMALDI, Madalena; PIRES, Julie (org.). Arquivos 30. Rio de Janeiro: Rio Books, 2020.

VILLAS-BOAS, André. Identidade e Cultura. Rio de Janeiro: 2AB, 2009.

WILLIAMS, Raymond. Base e superestrutura na teoria cultural marxista. Revista USP, São Paulo, n.65, mar./maio 2005. 